Review began 10/12/2021 Review ended 10/25/2021 Published 11/02/2021

\section{(๑) Copyright 2021}

Noor et al. This is an open access article distributed under the terms of the Creative Commons Attribution License CC-BY 4.0. which permits unrestricted use, distribution, and reproduction in any medium, provided the original author and source are credited.

\title{
Relationship of Homocysteine With Gender, Blood Pressure, Body Mass Index, Hemoglobin A1c, and the Duration of Diabetes Mellitus Type 2
}

Aqil Noor ${ }^{1}$, Mahboob Ur Rahman ${ }^{2}$, Noor Faraz ${ }^{3}$, Kashif A. Samin ${ }^{4}$, Hamid Ullah ${ }^{5}$, Amjad Ali ${ }^{5}$

1. Endocrinology, Hayatabad Medical Complex, Peshawar, PAK 2. Medicine, District Head Quarter Hospital, Peshawar, PAK 3. Cardiology, Lady Reading Hospital Medical Teaching Institution, Peshawar, PAK 4. Family Medicine, Khyber Medical University, Peshawar, PAK 5. Medicine, Bacha Khan Medical College, Mardan, PAK

Corresponding author: Aqil Noor, dr.aqilnoor@yahoo.com

\section{Abstract}

\section{Introduction}

Increased levels of homocysteine (Hcy) may lead to endothelial damage and increase the risk of cardiovascular and renal malfunction. The current study aimed to evaluate the association of serum Hcy levels with gender, body mass index (BMI), duration of diabetes mellitus type 2 (DMT2), hemoglobin A1c (HbA1c), and blood pressure (BP).

\section{Methodology}

A prospective observational study was conducted at Hayatabad Medical Complex in Peshawar, Pakistan in the department of endocrinology from June 2020 to June 2021. All patients with diagnosed DMT2 above the age of 18 years were included in the study. Individuals with unconfirmed diagnoses with ages over 75 years were excluded from the study. All data including the patient's age, gender, and medical history were recorded. Height and weight were used to calculate the BMI. BP was examined thrice and a mean value was recorded for each patient. For laboratory investigation, a vial of $3 \mathrm{ml}$ blood was extracted keeping sterile and aseptic conditions by a trained nurse. The sample was sent for the determination of HbA1c and serum Hcy levels. Measurement of serum Hcy was done by chemiluminescent microparticle immunoassay. All data were documented by the researchers on a predefined pro forma.

\section{Results}

A total of 188 patients with DMT2 were included in the study with a mean age \pm SD of $54.65 \pm 8.42$ years. Normal (<15 micromoles per liter [mcmol/1]) serum Hcy levels were reported in 75 (39.89\%) individuals, while in 47 (41.59\%) individuals, there was severe (>100 mcmol/l) hyperhomocysteinemia. More than half of the patients, i.e. 157 (83.52\%), had HbA1c of greater than 7\%, which indicated poor glycemic control. The study revealed that the majority of the female patients, i.e. 37 (78.72\%), had severe hyperhomocysteinemia $(\mathrm{p}<0.0001)$. Similarly, there was a direct correlation between HbA1c levels and serum Hcy. Severe hyperhomocysteinemia was found in over $80 \%$ of the patients with poor glycemic control, i.e. HbA1c $>7 \%$ $(\mathrm{p}<0.0001)$. Furthermore, the duration of DMT2 and hypertension were both significantly associated with increased levels of Hcy with p-values of $<0.0001$ and $<0.0001$, respectively. However, no association was found between hyperhomocysteinemia and BMI.

\section{Conclusion}

The study revealed that increased levels of serum Hcy were associated with female gender, poor glycemic control (HbA1c > 7\%), BP, and duration of DMT2. However, the study failed to find an association between serum Hcy and BMI. It is recommended that patients with poor glycemic control or those with the duration of DMT2 of more than five years must be regularly checked for hyperhomocysteinemia and renal function tests.

Large-scale and multi-center studies are required in order to determine the validity of these findings. The current study suggests that patients with diabetes mellitus and hypertension are likely to have increased levels of Hcy and, therefore, must be regularly screened for hyperhomocysteinemia.

Categories: Endocrinology/Diabetes/Metabolism, Family/General Practice, Internal Medicine

Keywords: hyperhomocysteinemia, hba1c, blood pressure, diabetes, hemoglobin, body mass index, hcy

\section{Introduction}

According to the World Health Organization (WHO), the percentage of individuals with diabetes mellitus type 2 (DMT2) was $2.8 \%$ in 2000 and would increase to $4.4 \%$ by the year 2030 . The increase in DMT2 cases from 171 million to 366 million in 30 years of duration since the last few decades was projected [1,2]. In 
1995, WHO survey found that Pakistan ranked eighth among the 10 countries with the highest prevalence of diabetes. The same survey estimated that Pakistan will rank fourth with 14.5 million people with diabetes in 2025 [3]. In 2012, seven million people had diabetes [4]. The prevalence of DMT2 in Pakistan in 2015 reached 7.89\% [5]. In other Southeast Asian countries, the percentage of patients with DMT2 varied greatly in the year 2014: Mauritius had a prevalence of $14.8 \%$, India with $9.1 \%$, Sri Lanka with $7.6 \%$, Bangladesh with $6.3 \%$, Bhutan with 5.8\%, Nepal with $4.9 \%$, and Maldives with 4.8\% [6]. The risk of developing peripheral neuropathy was related to age, hemoglobin A1c (HbA1c), duration of DMT2 as well as retinopathy or neuropathy [7].

Hyperhomocysteinemia is common in patients with renal failure because proper kidney function is critical to homocysteine (Hcy) metabolism [8,9]. Hyperhomocysteinemia increases the manufacturing of homocysteine thiolactone, oxidation products, Hcy thiolactone, and mixed Hcy disulfides thereby damaging endothelium by excessive connective tissue sulfation $[10,11]$. Ambrosch et al. showed an association of neuropathy with serum Hcy [12]. This connection was, however, not proved by other studies [13,14]. In addition, more literature have shown a connection between higher levels of plasma and the prevalence of other complications such as retinopathy and nephropathy, particularly in patients with DMT2 [13,15]. Other studies show that Hcy leads to endothelial damage. Normal levels of Hcy are less than 15 micromoles per liter (mcmol//); however, higher levels are responsible for endothelial damage, which can subsequently lead to coagulopathy, coronary artery disease, myocardial infarction, and strokes. Hcy metabolism plays a major role in the pathogenesis of microvascular complications in patients with DMT2 [16].

The literature of this part of the developing countries of the world seems deficient. Comprehensive and explorative research on this topic has not been done recently. Therefore, our purpose of the study was to find out the association of serum Hcy levels with gender, HbA1c, blood pressure (BP), body mass index (BMI), and duration of DMT2.

\section{Materials And Methods}

A prospective observational study was conducted at Hayatabad Medical Complex (HMC) in Peshawar, Pakistan in the department of endocrinology from June 2020 to June 2021. Prior to the study being conducted, ethical approval was obtained from the institutional review board of HMC \# IRB/26164/HMC. All diagnosed cases of DMT2, irrespective of gender and age above 18 years, were included in the study. All individuals with diabetes mellitus type 1, unconfirmed diagnosis of DMT2, age above 75 years, and those taking vitamin B supplements were excluded from the study. Informed verbal and written consent was obtained after the objectives and significance of the study were narrated to all the participants.

All data including the patient's age, gender, and medical history were recorded. Height and weight were used to calculate the BMI using the following formula: weight $(\mathrm{kg}) /[\text { height (meters) }]^{2}$. The patients were divided according to the categories of BMI, i.e. underweight $\left(<18 \mathrm{~kg} / \mathrm{m}^{2}\right)$, normal weight $\left(18-24.9 \mathrm{~kg} / \mathrm{m}^{2}\right)$, overweight $\left(>25.0-29.9 \mathrm{~kg} / \mathrm{m}^{2}\right)$, and obesity $\left(30.0 \mathrm{~kg} / \mathrm{m}^{2}\right.$ and above). BP was examined thrice using the auscultatory method and with the aid of a sphygmomanometer and a stethoscope. The mean of three values was recorded for each patient. The patients were labeled as hypertensive if the systolic BP was over $140 \mathrm{mmHg}$ and the diastolic was over $90 \mathrm{mmHg}$ on at least two different occasions.

For laboratory investigation, a vial of $3 \mathrm{ml}$ blood was extracted keeping sterile and aseptic conditions by a trained nurse. Patients were instructed to fast before arrival for the blood sample extraction. The sample was sent for the determination of HbA1c and Hcy levels. HbA1c was determined by centrifugation in a Beckman Allegra Tm 6R centrifuge at 3000 revolutions per minute for at least 10-15 minutes. Once the plasma was separated, it was shifted into Eppendorf tubes and was frozen at $-80^{\circ} \mathrm{C}$ for analysis of the Hcy. Measurement of Hcy was done by chemiluminescent microparticle immunoassay. The HbA1c of greater than $7 \%$ was labeled as poor glycemic control and the HbA1c of less than $7 \%$ indicated good glycemic control. The serum Hcy levels were categorized into the following: normal ( $<15 \mathrm{mcmol} / \mathrm{l})$, moderate $(15-30 \mathrm{mcmol} / \mathrm{l})$, intermediate (30-100 $\mathrm{mcmol} / \mathrm{l})$, and severe (>100 $\mathrm{mcmol} / \mathrm{l})$.

The data regarding sociodemographics, clinical history, and laboratory investigations were documented in a predefined pro forma. Data analysis was performed using Statistical Package for Social Sciences (SPSS version 23 [IBM Corp, Armonk, NY]). For continuous variables (BMI, age, Hcy levels, BP, HbA1c, and duration of DMT2), the mean \pm SD were determined. For categorical variables (gender, categories of BMI, HbA1c, etc.), frequencies and percentages were calculated. The chi-squared test was applied to find out the association of Hcy levels with BP, BMI, and duration of DMT2. A p-value of less than or equal to 0.05 was taken as the cutoff for statistical significance.

\section{Results}

A total of 188 patients with DMT2 were included in the study with a mean age \pm SD of $54.65 \pm 8.42$ years. The baseline characteristics of the study participants are presented in Table 1. 


\section{Cureus}

\section{Characteristics}

Age (in years)

Body mass index (in $\mathrm{kg} / \mathrm{m}^{2}$ )

Systolic blood pressure $(\mathrm{mmHg})$

Diastolic blood pressure $(\mathrm{mmHg})$

Serum homocysteine (in $\mathrm{mcmol} / \mathrm{l}$ )

Duration of DMT2 (in years)
Mean \pm SD

$54.65 \pm 8.42$

$29.5 \pm 5.02$

$139 \pm 21.78$

$88.73 \pm 14.70$

$92.45 \pm 15.52$

$7.69 \pm 6.76$

TABLE 1: Characteristics of Study Patients ( $n=188$ )

DMT2: diabetes mellitus type 2

There was female dominance with a frequency of 108 (57.44\%). Normal ( $<15 \mathrm{mcmol} / \mathrm{l})$ serum Hcy levels were reported in 75 (39.89\%) individuals, while in 47 (41.59\%) individuals, there was severe (>100 mcmol/l) hyperhomocysteinemia. More than half of the patients had HbA1c of greater than $7 \%$, which indicated poor glycemic control (Table 2).

\section{Characteristics}

Gender

Male

Female

Body mass index

Healthy weight $\left(18.5-24.9 \mathrm{~kg} / \mathrm{m}^{2}\right)$

Overweight $\left(25.0-29.9 \mathrm{~kg} / \mathrm{m}^{2}\right)$

Obesity ( $30.0 \mathrm{~kg} / \mathrm{m}^{2}$ and above)

Serum homocysteine levels

Normal (<15 mcmol/l)

Moderate $(15-30 \mathrm{mcmol} / \mathrm{l})$

Intermediate (30-100 $\mathrm{mcmol} / \mathrm{l})$

Severe $(>100 \mathrm{mcmol} / \mathrm{l})$

Glycemic contro

Good glycemic control $(\mathrm{HbA} 1 \mathrm{c}<7 \%)$

Poor glycemic control (HbA1c > $7 \%$ )

Hypertension

Yes

No
N (\%)

$80(42.66 \%)$

$108(57.44 \%)$

$62(32.97 \%)$

$88(46.81 \%)$

$38(22.21 \%)$

$75(39.89 \%)$

$24(21.24 \%)$

$42(37.17 \%)$

$47(41.59 \%)$

$31(16.48 \%)$

$157(83.52 \%)$

$79(42.01 \%)$

$109(57.98 \%)$

TABLE 2: Categorical Parameters of Study Participants ( $n=188)$

HbA1c: hemoglobin A1c

The study revealed that the majority of the female patients, i.e. 37 (78.72\%), had severe 


\section{Cureus}

hyperhomocysteinemia ( $<0.0001)$. Similarly, there was a direct correlation between HbA1c levels and serum Hcy. Severe hyperhomocysteinemia was found in over $80 \%$ of the patients with poor glycemic control, i.e. HbA1c > 7\% ( $p<0.0001)$. Furthermore, the durations of DMT2 and hypertension are both significantly associated with increased levels of homocysteinemia with p-values of $<0.0001$ and $<0.0001$, respectively. However, no association was found between hyperhomocysteinemia and BMI (Table 3).

\begin{tabular}{|c|c|c|c|c|c|}
\hline \multirow[t]{2}{*}{ Parameter(s) } & \multicolumn{4}{|c|}{ Serum Homocysteine Levels } & \multirow[t]{2}{*}{ p-Value } \\
\hline & $\begin{array}{l}\text { Normal (<15 } \\
\mathrm{mcmol} / \mathrm{l})\end{array}$ & $\begin{array}{l}\text { Moderate (15-30 } \\
\mathrm{mcmol} / \mathrm{l})\end{array}$ & $\begin{array}{l}\text { Intermediate (30-100 } \\
\mathrm{mcmol} / \mathrm{l})\end{array}$ & $\begin{array}{l}\text { Severe (>100 } \\
\mathrm{mcmol} / \mathrm{l})\end{array}$ & \\
\hline \multicolumn{6}{|l|}{ Gender } \\
\hline Male $(n=80)$ & $52(69.33 \%)$ & $7(29.17 \%)$ & $11(26.19 \%)$ & $10(21.28 \%)$ & $<0.0001$ \\
\hline Female (n=108) & $23(30.61 \%)$ & $1 /(/ 0.83 \%)$ & $31(/ 3.81 \%)$ & $3 /(18.12 \%)$ & \\
\hline \multicolumn{6}{|l|}{ Body mass index } \\
\hline Healthy weight (n=62) & $24(32 \%)$ & $10(41.7 \%)$ & $11(26.2 \%)$ & $17(36.2 \%)$ & 0.524 \\
\hline Overweight (n=88) & $38(50.7 \%)$ & $10(41.7 \%)$ & $23(54.8 \%)$ & $17(36.2 \%)$ & \\
\hline Obesity $(n=38)$ & $13(17.3 \%)$ & $4(16.7 \%)$ & $8(19 \%)$ & $13(27.7 \%)$ & \\
\hline \multicolumn{6}{|l|}{ Glycemic control } \\
\hline HbA1c <7\% (n=31) & $8(10.7 \%)$ & $5(20.8 \%)$ & $10(23.8 \%)$ & $8(17 \%)$ & $<0.0001$ \\
\hline HbA1c >7\% (n=157) & $67(89.3 \%)$ & $19(79.2 \%)$ & $32(76.2 \%)$ & $39(83 \%)$ & \\
\hline \multicolumn{6}{|l|}{ Duration of DMT2 } \\
\hline Less than five years $(n=70)$ & $42(56 \%)$ & $8(33.3 \%)$ & $13(31 \%)$ & $7(14.9 \%)$ & $<0.0001$ \\
\hline $\begin{array}{l}\text { Five years or greater } \\
(n=118)\end{array}$ & $33(44 \%)$ & $16(66.7 \%)$ & $29(69 \%)$ & $40(85.1 \%)$ & \\
\hline \multicolumn{6}{|l|}{ Hypertension } \\
\hline Yes (n=79) & $10(13.3 \%)$ & $10(41.7 \%)$ & $25(59.5 \%)$ & $34(72.3 \%)$ & $<0.0001$ \\
\hline No $(n=109)$ & 65 (86.7\%) & $14(58.3 \%)$ & $17(40.5 \%)$ & $13(27.7 \%)$ & \\
\hline
\end{tabular}

TABLE 3: The Association of Serum Homocysteine Levels With Gender, Body Mass Index, Glycemic Control, Duration of DMT2, and Hypertension ( $n=188)$

HbA1c: hemoglobin A1c; DMT2: diabetes mellitus type 2

\section{Discussion}

According to the results of our study, there was a direct association of serum Hcy with poor glycemic control as well as the duration of DMT2. Furthermore, the study also found that the majority of the patients with severe hyperhomocysteinemia were females. Finally, upon further assessment, it was revealed that hypertension was significantly correlated with increased levels of serum Hcy. Our study was comparable with the findings of Shaikh et al. [17]. In contrast to our study, Hoogeven et al. reported no significant link between serum Hcy and inadequate glycemic control [18]. Agha mohammadi et al. examined the association between HbA1c and serum Hcy in patients with DMT2 and failed to report any significant correlation between the two [19]. Pouwels et al. claimed the similar findings [20].

The present study failed to find an association between serum Hcy and the BMI. A study conducted in Kenya reported similar results and demonstrated no correlation between BMI and serum Hcy levels [21]. Other studies revealed similar results [22]. The link between obesity and hyperhomocysteinemia remains controversial. For future researches, the authors aim to evaluate the relationship between hypercholesteremia and hyperhomocysteinemia.

We found a positive correlation between hypertension and increased levels of serum Hcy. Since hyperhomocysteinemia is known to damage the endothelial layer and also impact kidney function, this finding was not unexpected. Passaro et al. found similar associations [23]. However, some studies failed to 
It was found that the greater the duration of DMT2, the higher the levels of Hcy in the plasma. Coinciding results were observed by Sonkar et al. where the authors reported a significant association of plasma levels of Hcy and the duration and complications of DMT2 [24]. A study on patients presenting with diabetic retinopathy also reported a positive association of the duration of DMT2 with hyperhomocysteinemia [25]. Similarly, Mundu PA et al. found a direct relationship between duration of DMT2 and increased levels of serum Hcy [26].

In conclusion, we can suggest that hyperhomocysteinemia in patients with DMT2 directly depends on gender, BP, duration of DMT2, and poor glycemic control. However, the current study has some limitations. For instance, the current study was conducted only in a single institution and recruited only a limited number of patients owing to the resource and time restraints. Thus, the findings of the current study cannot be generalized to a larger population. Therefore, further studies with large and diversified sample sizes are recommended.

\section{Conclusions}

The study revealed that increased levels of serum Hcy were associated with female gender, poor glycemic control (HbA1c >7\%), BP, and duration of DMT2. However, the study failed to find an association between serum Hcy and the BMI. It is recommended that patients with poor glycemic control or those with the duration of DMT2 of more than five years must be regularly checked for hyperhomocysteinemia and renal function.

Large-scale and multi-center studies are required in order to determine the validity of these findings. The current study suggests that patients with diabetes mellitus and hypertension are likely to have increased levels of Hcy and, therefore, must be regularly screened for hyperhomocysteinemia and subsequent renal failure.

\section{Additional Information \\ Disclosures}

Human subjects: Consent was obtained or waived by all participants in this study. Hayatabad Medical Complex (HMC) issued approval IRB/26164/HMC. This is to inform you that the study topic entitled, "Association of Homocysteine With Gender, Body Mass Index (BMI), Blood Pressure, Hemoglobin A1c (HbA1c) and Duration of Diabetes in Type 2 Diabetics" has been approved by the committee. Animal subjects: All authors have confirmed that this study did not involve animal subjects or tissue. Conflicts of interest: In compliance with the ICMJE uniform disclosure form, all authors declare the following: Payment/services info: All authors have declared that no financial support was received from any organization for the submitted work. Financial relationships: All authors have declared that they have no financial relationships at present or within the previous three years with any organizations that might have an interest in the submitted work. Other relationships: All authors have declared that there are no other relationships or activities that could appear to have influenced the submitted work.

\section{References}

1. American Diabetes Association: Diagnosis and classification of diabetes mellitus. Diabetes Care. 2014, 37 Suppl 1:S81-90. 10.2337/dc14-S081

2. Wild S, Roglic G, Green A, Sicree R, King H: Global prevalence of diabetes: estimates for the year 2000 and projections for 2030. Diabetes Care. 2004, 27:1047-53. 10.2337/diacare.27.5.1047

3. Gaziano TA: Cardiovascular disease in the developing world and its cost-effective management . Circulation. 2005, 112:3547-53. 10.1161/CIRCULATIONAHA.105.591792

4. Ramachandran A, Snehalatha C, Shetty AS, Nanditha A: Trends in prevalence of diabetes in Asian countries . World J Diabetes. 2012, 3:110-7. 10.4239/wjd.v3.i6.110

5. Ansari RM, Dixon JB, Coles J: Type 2 diabetes: challenges to health care system of Pakistan. Int J Diabetes Res. 2015, 4:7-12. 10.5923/i.diabetes.20150401.02

6. Ramachandran A, Snehalatha C, Ma RC: Diabetes in South-East Asia: an update . Diabetes Res Clin Pract. 2014, 103:231-7. 10.1016/j.diabres.2013.11.011

7. Barrell K, Smith AG: Peripheral neuropathy. Med Clin North Am. 2019, 103:383-97. 10.1016/j.mcna.2018.10.006

8. Hoffer LJ: Testing the homocysteine hypothesis in end-stage renal disease: problems and a possible solution. Kidney Int. 2006, 69:1507-10. 10.1038/sj.ki.5000279

9. Ruan L, Chen W, Srinivasan SR, Xu J, Toprak A, Berenson GS: Plasma homocysteine is adversely associated with glomerular filtration rate in asymptomatic black and white young adults: the Bogalusa heart study. Eur J Epidemiol. 2009, 24:315-9. 10.1007/s10654-009-9340-0

10. Starkebaum G, Harlan JM: Endothelial cell injury due to copper-catalyzed hydrogen peroxide generation from homocysteine. J Clin Invest. 1986, 77:1370-6. 10.1172/JCI112442

11. Stamler JS, Osborne JA, Jaraki O, Rabbani LE, Mullins M, Singel D, Loscalzo J: Adverse vascular effects of homocysteine are modulated by endothelium-derived relaxing factor and related oxides of nitrogen. J Clin Invest. 1993, 91:308-18. 10.1172/JCI116187 
12. Ambrosch A, Dierkes J, Lobmann R, Kühne W, König W, Luley C, Lehnert H: Relation between homocysteinaemia and diabetic neuropathy in patients with type 2 diabetes mellitus. Diabet Med. 2001, 18:185-92. 10.1046/j.1464-5491.2001.00445.x

13. Cohen JA, Jeffers BW, Stabler S, Schrier RW, Estascio R: Increasing homocysteine levels and diabetic autonomic neuropathy. Auton Neurosci. 2001, 87:268-73. 10.1016/S1566-0702(00)00262-9

14. de Luis DA, Fernandez N, Arranz ML, Aller R, Izaola O, Romero E: Total homocysteine levels relation with chronic complications of diabetes, body composition, and other cardiovascular risk factors in a population of patients with diabetes mellitus type 2. J Diabetes Complications. 2005, 19:42-6. 10.1016/j.jdiacomp.2003.12.003

15. Vaccaro O, Perna A, Mancini F, et al.: Plasma homocysteine and microvascular complications in type 1 diabetes. Nutr Metab Cardiovasc Dis. 2000, 10:297-304.

16. Papatheodorou L, Weiss N: Vascular oxidant stress and inflammation in hyperhomocysteinemia. Antioxid Redox Signal. 2007, 9:1941-58. 10.1089/ars.2007.1750

17. Shaikh MK, Devrajani BR, Shaikh A, Shah SZ, Shaikh S, Singh D: Plasma homocysteine level in patients with diabetes mellitus. World Appl Sci J. 2012, 16:1269-73.

18. Hoogeveen EK, Kostense PJ, Jakobs C, et al.: Hyperhomocysteinemia increases risk of death, especially in type 2 diabetes: 5-year follow-up of the Hoorn Study. Circulation. 2000, 101:1506-11. 10.1161/01.cir.101.13.1506

19. Aghamohammadi V, PourghassemGargari B, Aliasgharzadeh A: Evaluation of the level of plasma homocysteine in patients with type 2 diabetes mellitus under metformin treatment and its correlation with serum total antioxidant capacity, malondialdehyde, creatinine, insulin resistance and glycemic control. J Adv Med Biomed Res. 2011, 19:1-10.

20. Pouwels MJ, Den Heijer M, Blom HJ, Tack CJ, Hermus AR: Improved insulin sensitivity and metabolic control in type 2 diabetes does not influence plasma homocysteine. Diabetes Care. 2003, 26:1637-9. 10.2337/diacare.26.5.1637

21. Martín-Timón I, Sevillano-Collantes C, Segura-Galindo A, Del Cañizo-Gómez FJ: Type 2 diabetes and cardiovascular disease: have all risk factors the same strength?. World J Diabetes. 2014, 5:444-70. 10.4239/wjd.v5.i4.444

22. Tarkun I, Arslan B, Cantürk Z, Tarkun P, Kozdağ G, Topsever P: Homocysteine concentrations in type 2 diabetes mellitus patients without cardiovascular disease: relationship to metabolic parameters and diabetic complications. Turk J Endocrinol Metab. 2003, 1:11-7.

23. Passaro A, Calzoni F, Volpato S, et al.: Effect of metabolic control on homocysteine levels in type 2 diabetic patients: a 3-year follow-up. J Intern Med. 2003, 254:264-71. 10.1046/j.1365-2796.2003.01184.x

24. Sonkar SK, Sonkar GK, Soni D, Soni D, Usman K: Plasma homocysteine level and its clinical correlation with type 2 diabetes mellitus and its complications. Int J Diabetes Dev Ctries. 2014, 34:3-6. 10.1007/s13410-013$0154-\mathrm{y}$

25. Huang EJ, Kuo WW, Chen YJ, et al.: Homocysteine and other biochemical parameters in type 2 diabetes mellitus with different diabetic duration or diabetic retinopathy. Clin Chim Acta. 2006, 366:293-8. 10.1016/j.cca.2005.10.025

26. Mundu PA, Kumar B, Mitra JK, Kumar M, Sinha R: Study of assessment of plasma homocysteine level in microvascular complications of type 2 diabetes mellitus. Int J Contemporary Med Res. 2017, 4:879-83. 